\title{
Effect of Carbon, Nitrogen Sources and Water Activity on Growth and Ochratoxin Production of Aspergillus carbonarius (Bainier) Thom
}

\author{
Abeer Hashem ${ }^{1, *}$; Elsayed Fathi Abd-Allah ${ }^{2}$; Rashid Sultan Al-Obeed ${ }^{2}$; Abdulaziz Abdullah \\ Alqarawi ${ }^{2} ;$ Hend Awad Alwathnani ${ }^{3}$ \\ 1 Department of Mycology and Plant Disease Survey, Plant Pathology Research Institute, Agriculture Research Center, Giza, Egypt \\ 2 Plant Production Department, Faculty of Food and Agricultural Sciences, King Saud University, Riyadh, Saudi Arabia \\ ${ }^{3}$ Botany and Microbiology Department, Faculty of Science, King Saud University, Riyadh, Saudi Arabia \\ ${ }^{*}$ Corresponding author: Abeer Hashem, Mycology and Plant Disease Survey Department, Plant Pathology Research Institute, Agriculture Research Center, Giza, Egypt. Tel: +9611 \\ 300110, E-mail: habeer@ksu.edu.sa
}

Received: January 13, 2014; Revised: May 13, 2014; Accepted: May 22, 2014

\begin{abstract}
Background: Ochratoxin A (OTA) is a toxic secondary metabolite produced by fungi belonging to Aspergillus and Penicillium genera. The production of OTA is influenced by environmental conditions and nutritional requirements. The postharvest application of bunches of table grape fruit(TGF), with water activity of $0.8 \mathrm{a}_{\mathrm{w}}$, was highly effective for controlling OTA contamination in vitro and in vivo (table grape). Objectives: The aim of this study was to determine the influence of environmental conditions and nutritional requirements on growth and OTA production by Aspergillus carbonarius, as well as, the impact of water activity on OTA production and growth characters of $A$. carbonarius. Furthermore, we also examined the influence of the application of different levels of water activity $\left(\mathrm{a}_{\mathrm{w}} 0.8\right)$ on the preservation of the general appearance of TGF and control of their contamination with OTA.

Materials and Methods: The growth and OTA production by A. carbonarius were studied using glucose-ammonium nitrate salt broth medium. Effect of water activity was studied using glycerol $\left(0.80,0.85,0.90\right.$, and $\left.0.98 \mathrm{a}_{\mathrm{w}}\right)$. The bunches of table grape fruits were immersed in glycerol solution (equivalent to $0.80 \mathrm{a}_{\mathrm{w}}$ ) and placed as a double layer in cardboard boxes $\left(25 \times 35 \times 10 \mathrm{~cm}\right.$ ). The boxes were stored at $20^{\circ} \mathrm{C}$ for 15 days to simulate local market conditions.

Results: The maximum OTA production by A. carbonarius was observed on broth medium after eight days of incubation at $20^{\circ} \mathrm{C}$, with $\mathrm{pH} 4$, and fructose and ammonium nitrate supplementation as carbon and nitrogen sources, respectively. The water activity $(0.9,0.85$ $\mathrm{a}_{\mathrm{w}}$ ) caused significant decrease in OTA production by A. carbonarius. The postharvest application of water activity $\left(0.8 \mathrm{a}_{\mathrm{w}}\right)$ was highly effective for maintenance of the table grape quality, which was expressed as weight loss, firmness and decay, while it also controlled OTA contamination of fruits under concept of local market conditions.

Conclusions: Our results reported that deterioration of TGF by A. carbonarius could be minimized by application of $\mathrm{a}_{\mathrm{w}^{*}}$. Our experiments were performed under conditions of local markets, which support the economy of many thousands of families in Egypt, especially in the poor rural areas. In future adequate research is required to use these technologies commercially.
\end{abstract}

Keywords: Aspergillus; Temperature; Carbon; Nitrogen; Ochratoxin A

\section{Background}

Ochratoxin A (OTA) is a toxic secondary metabolite produced by fungi belonging to Aspergillus and Penicillium genera (1). It has been reported as a nephrotoxic, teratogenic and immunosuppressive agent (2). It also has been demonstrated to be a carcinogenic as well as genotoxic agent for mammals causing an increase in DNA damage (3), hence increasing mutation frequencies (2). The contamination of table grape fruits (TGF) with OTA has been reported especially in developing countries like Egypt, causing health risk for both animals and humans $(4,5)$. Aspergillus carbonarius is one of the prominent fungal species that produces OTA and attacks many postharvest fruits including TGF during storage and handling (6).

The moldy growth on the surface of grape berries causes significant decrease in the quality of fruit (7) and leads to decrease in market value of the fruit. The patho- logical handling and lack of deterioration of TGF could reach 50\% in some developing countries such as in Egypt (8) due to improper methods to prevent decay (8). Preservation of quality and extension of shelf life of TGF will help in exporting the fruit to distant markets, increasing the foreign exchange income and will support the economy of thousands of families in Egypt. Growth and OTA production by $A$. carbonarius are mainly dependent on environmental conditions and nutritional composition of the surrounding medium. These two key factors have been reported to regulate the spoilage and contaminating activity of this mold (9). The use of chemical fungicides is a principal procedure and has been used to control postharvest fungal attacks on fruits (10).

Currently several chemical fungicides have been rejected and removed from the market due to their possible

Copyright (C) 2015, Ahvaz Jundishapur University of Medical Sciences. This is an open-access article distributed under the terms of the Creative Commons Attribution-NonCommercial 4.0 International License (http://creativecommons.org/licenses/by-nc/4.0/) which permits copy and redistribute the material just in noncommercial usages, provided the original work is properly cited. 
Hashem A et al.

toxicological risks (11). At present, there is an urgent need to develop a non-toxic alternative to control postharvest molds and bioremediation of their mycotoxins $(11,12)$. Water activity $\left(a_{w}\right)$ is the ratio of vapor pressure of water in a material to the vapor pressure of pure water at the same temperature. Many studies have suggested that $\mathrm{a}_{\mathrm{w}}$ is an abiotic non-chemical stress which directly influences the growth as well as metabolic activities of fungal species (13). However a few studies have reported on the inhibitory effect of $\mathrm{a}_{\mathrm{w}}$ on growth and OTA production by A. carbonarius. Magan et al. (14) reported that growth and OTA production by $A$. carbonarius were significantly inhibited with a decrease of $\mathrm{a}_{\mathrm{w}}$ (increase water potential). The decrease of $a_{w}$ had an impact on spore germination, germ tube extension and colony growth of black mold (A. niger), which may have been the mechanisms for the observed inhibition (15). This approach enables the protection of fresh fruits during handling and marketing against attacks by $A$. carbonarius.

\section{Objectives}

The aim of this study was to determine the influence of environmental conditions and nutritional requirements on growth and OTA production of A. carbonarius. Moreover, at the optimum culture conditions, we also studied the impact of water activity on OTA production and growth characters of the experimental mold. Furthermore, we also examined the application of different levels of water activity $\left(\mathrm{a}_{\mathrm{w}} 0.8\right)$ to preserve the general appearance of TGF and to control their contamination with OTA.

\section{Materials and Methods}

\subsection{The Experimental Mold}

The experimental mold (Aspergillus carbonarius (Bainier) Thom) was isolated from Egyptian table grape fruit samples collected from the local market in Sharkia Governorate, Egypt, and was identified according to methods of Raper and Fennell (16).

\subsection{General Culture Conditions}

The growth and OTA production by A. carbonarius were studied using glucose-ammonium nitrate salt broth medium (17). Basal medium was used to study the effect of $\mathrm{pH}$ value on growth and OTA production. Citrate-phosphate buffer was used to adjust the $\mathrm{pH}$ value of the medium. The basal C and $\mathrm{N}_{2}$ sources of the growth medium were substituted with equivalent amounts of other sources, to study the effect of $\mathrm{C}$ and $\mathrm{N}_{2}$, respectively.

\subsection{Effect of Water Activity aw}

For maximum production of OTA, the growth medium was supplemented with glycerol/l to achieve levels of
0.80, 0.85, 0.90, and $0.98 \mathrm{a}_{\mathrm{w}}$, according to Pardo et al. (18). Final $\mathrm{a}_{\mathrm{w}}$ values were checked with a water activity meter (Aqua Lab, Pullman, WA, USA). Control flasks were used as references.

\subsection{Estimation of Ochratoxin A}

The extraction of OTA was carried out by chloroform from both culture filtrate and table grape fruits (postharvest experiment), according to the methods described by Scott (19). Thin layer chromatography (TLC) plates $(20 \times 20 \mathrm{~cm})$ coated with $0.3 \mathrm{~mm}$-thick silica gel DG (Kieselgel-DG, Riedel-De Haen, Seelze-Hannover, Germany) was used for the chromatographic separation of OTA. The plates were developed with toluene: ethyl acetate: formic acid $(5: 4: 1, \mathrm{v} / \mathrm{v} / \mathrm{v})$ as a mobile system. The plates were examined under ultraviolet light illumination (366 nm) and standard OTA (Sigma-Aldrich, Steinheim, Germany) was used as a reference. The illusion of OTA spots was carried out using benzene: acetonitrile $(98: 2, \mathrm{v} / \mathrm{v})$. The eluted extract was filtered (Millex-HV; Millipore Corporation, Bedford, USA) and a volume of 5.0 $\mu \mathrm{L}$ was analyzed by High Performance Liquid chromatography (HPLC) (Schimadzu Corporation, Japan). A mobile phase consisting of acetonitrile: water: acetic acid (99:99:2, v/v/v) was used for the resolution of OTA on a C18 Hypersil column, as described by Aboul-Enein et al. (20). The excitation and emission wavelengths were set at 385 and $435 \mathrm{~nm}$, respectively (21). Ochratoxin A was quantified by comparison with a calibration curve of OTA standards according to Valero et al. (22) using the Shimadzu CLASS-VP software version 6.14 SP2 (Shimadzu Corporation, Japan). Standard OTA (Sigma-Aldrich, Steinheim, Germany) was used as a reference.

\subsection{Storage Experiment}

Healthy, ripe and fresh bunches of Vitis vinifera L. CV Thompson were collected from the local orchard (Nobarya, Alexandria, Egypt) throughout the production season of 2012. The bunches were immersed in glycerol solution (equivalent to $0.80 \mathrm{a}_{\mathrm{w}}$ ) supplemented with $(0.05 \%$ $\mathrm{w} / \mathrm{v}$ ) carboxymethyl cellulose, as an adhesive agent, and placed as a double layer in cardboard boxes $(25 \times 35 \times 10$ $\mathrm{cm}$ ) with apertures for aeration. The cardboard boxes were inoculated with A. carbonarius as one disc/box (agar disc [10 $\mathrm{mm}$ in diameter] of a seven-day old culture was used). The boxes were stored at $20^{\circ} \mathrm{C}$ for 15 days to simulate local market conditions. Control boxes were used as reference. Each experiment was repeated three times. At the end of the postharvest experiment, contamination with OTA, decay incidence and firmness were used as sensitive monitors for the impact of postharvest treatment with glycerol $\left(0.80 \mathrm{a}_{\mathrm{w}}\right)$ on berry quality. Decay incidence was expressed as the proportion by weight of berry cheek rot or berry base rot relative to total grape weight according to Holz et al. (23). Firmness was individually recorded as five, very hard; four, hard; three, moderately firm; two, slightly firm and one, soft (8). 
Hashem A et al.

\subsection{Statistical Analysis}

All experiments were repeated three times. The data were statistically analyzed using analysis of variance for a completely randomized design.

\section{Results}

In the present study, we investigated the impact of some environmental conditions and nutritional requirements for growth and OTA production by A. carbonarius. Additionally, we studied the effect of different concentrations of water activity (aw) on growth and OTA production by the mold under in vitro and in vivo (on table grape fruits) conditions. Moreover, the general appearance of grape clusters was studied under storage conditions.

The effect of incubation period on growth and production of extracellular as well as kinetic production of OTA by A. carbonarius is reported in Table 1. Growth and OTA production increased gradually with maximum amounts reached after ten and eight days, respectively. However, the optimum incubation period for kinetic production of OTA was eight days (Table 1). Thereafter, increase in incubation period was accompanied with a decrease in growth and OTA production.

The results in Table 2 indicate that A. carbonarius was able to grow at a wide range of incubation temperatures $\left(10-40^{\circ} \mathrm{C}\right)$ with optimum growth at $25^{\circ} \mathrm{C}$. The optimum temperatures for extracellular and kinetic OTA production were $20^{\circ} \mathrm{C}$ and $15^{\circ} \mathrm{C}$, respectively (Table 2). Further increase in temperature of more than $20^{\circ} \mathrm{C}$ and $25^{\circ} \mathrm{C}$ significantly decreased OTA production and growth of $A$. carbonarius, respectively. At $40^{\circ} \mathrm{C}$ A carbonarius showed very weak growth and no sign of OTA production. The increase in mycelial growth and extracellular production of OTA by A. carbonarius is directly proportional to increase in $\mathrm{pH}$ up to 4.5 and 4.0 , respectively and after this point a decrease was observed with increase in $\mathrm{pH}$ value (Table 3 ).
In the present study both growth and OTA production of A. carbonarius were variable with different carbon sources. No significant difference was observed between fructose, sucrose and glucose, which were the most suitable carbon sources for maximum mycelial growth compared with other carbon sources (Table 4). Also it is important to mention that fructose was the best for extracellular and kinetic OTA production (Table 4). Minimum growth and OTA production were detected with glycerol as the sole carbon source followed by pectin and cellulose (Table 4). The results related to the effect of different nitrogen sources on growth and OTA production and kinetic production of OTA by A. carbonarius are depicted in Table 5. Organic (peptone and yeast extract) and inorganic (sodium nitrates, potassium nitrates, ammonium nitrate, ammonium chloride, ammonium sulfate, ammonium phosphate and urea) nitrogen sources showed a significant impact on growth, OTA production and kinetic OTA production by A. carbonarius. Maximum growth and OTA production were reported for yeast extract followed by ammonium nitrate. However less effect was observed with ammonium chloride and urea (Table 5).

The current investigation indicated the impact of aw on growth and OTA production by A. carbonarius and provided information about inhibitory concentrations needed to stop mold activities (Table 6). The results showed that mycelial growth, spore germination, germ tube length and OTA production increases significantly to $28.01 \%$, $5.14 \%, 21.32 \%$ and $35.05 \%$, respectively at aw of 0.98 as compared to the control. As shown in Table 7, the postharvest application of glycerol $(0.8, \mathrm{aw})$ to TGF caused significant control OTA contamination and preserve the general appearance of grape clusters. The level of aw was determined based on a previous experiment. Apparently, water activity could reduce OTA production by $96.7 \%$ and the deterioration of fruit quality, which is expressed as weight loss, firmness and decay, by $85.5 \%, 71.3 \%$ and $94.9 \%$, respectively as compared to the control.

Table 1. Effect of Incubation Period (Days) on Growth (g/100 mL), Ochratoxin A Production and Kinetic Production of Ochratoxin A by Aspergillus carbonarius

\begin{tabular}{lccc}
\hline Incubation Period, Day & Growth, $\mathbf{g} / \mathbf{1 0 0} \mathbf{~ m L}$ & OTA Production, $\mu \mathbf{g} / \mathbf{1 0 0} \mathbf{~ m L}$ & Kinetic Production of OTA \\
\hline $\mathbf{2}$ & 0.23656 & 3.06 & 13.26289 \\
$\mathbf{4}$ & 0.63204 & 12.358 & 19.75073 \\
\hline $\mathbf{6}$ & 0.92486 & 30.858 & 33.39574 \\
$\mathbf{8}$ & 1.30014 & 80.42 & 61.7377 \\
\hline $\mathbf{1 0}$ & 1.33982 & 52.318 & 39.12026 \\
\hline $\mathbf{1 2}$ & 1.25158 & 41.66 & 33.27536 \\
\hline $\mathbf{1 4}$ & 1.045086 & 32.682 & 31.30253 \\
\hline LSD at: $\mathbf{0 . 0 5}{ }^{\mathrm{a}}$ & 0.0709 & 6.6451 & 5.6536 \\
\hline
\end{tabular}

\footnotetext{
a Abbreviation: Least Significant Difference.
} 
Table 2. Effect of Incubation Temperature $\left({ }^{\circ} \mathrm{C}\right)$ on Growth $(\mathrm{g} / 100 \mathrm{~mL})$, Ochratoxin A Production and Kinetic Production of Ochratoxin A by Aspergillus carbonarius

\begin{tabular}{lccc}
\hline Incubation Temperature, ${ }^{\circ} \mathbf{C}$ & Growth, $\mathbf{g} / \mathbf{1 0 0} \mathbf{~} \mathbf{L}$ & OTA Production, $\mu \mathbf{g} / \mathbf{1 0 0} \mathbf{~} \mathbf{L}$ & Kinetic Production of OTA \\
\hline $\mathbf{1 0}$ & 0.5995 & 15.816 & 26.69286 \\
$\mathbf{1 5}$ & 0.9103 & 77.818 & 85.53747 \\
\hline $\mathbf{2 0}$ & 1.2386 & 78.63 & 63.64386 \\
$\mathbf{2 5}$ & 1.5420 & 50.266 & 32.87429 \\
\hline $\mathbf{3 0}$ & 1.4707 & 29.564 & 20.08778 \\
\hline $\mathbf{3 5}$ & 1.4965 & 10.306 & 6.901443 \\
\hline $\mathbf{4 0}$ & 0.7882 & 0.0 & 0.0 \\
\hline LSD at: $\mathbf{0 . 0 5}^{\text {a }}$ & 0.0931 & 7.1934 & 6.6229 \\
\hline
\end{tabular}

a Abbreviation: Least Significant Difference.

Table 3. Effect of Incubation $\mathrm{pH}$ on Growth $(\mathrm{g} / 100 \mathrm{~mL})$, Ochratoxin A Production and Kinetic Production of Ochratoxin A by Aspergillus carbonarius

\begin{tabular}{lccc}
\hline Incubation $\mathbf{~ H ~}$ & Growth, $\mathbf{g} / \mathbf{1 0 0} \mathbf{~} \mathbf{L}$ & OTA Production, $\boldsymbol{\mu} \mathbf{g} / \mathbf{1 0 0} \mathbf{~ m L}$ & Kinetic Production of OTA \\
\hline $\mathbf{2 . 5}$ & 0.69916 & 23.534 & 33.73161 \\
\hline $\mathbf{3}$ & 1.01008 & 30.426 & 30.24016 \\
\hline $\mathbf{3 . 5}$ & 1.32186 & 60.802 & 46.20108 \\
\hline $\mathbf{4 . 0}$ & 1.63468 & 96.124 & 58.99921 \\
\hline $\mathbf{4 . 5}$ & 1.86454 & 78.078 & 41.88836 \\
\hline $\mathbf{5 . 0}$ & 1.30788 & 50.244 & 39.05087 \\
\hline $\mathbf{5 . 5}$ & 0.80666 & 23.138 & 29.07306 \\
\hline $\mathbf{6 . 0}$ & 0.5015 & 0.0 & 0.0 \\
\hline LSD at: $\mathbf{0 . 0 5}{ }^{\text {a }}$ & 0.1433 & 7.0466 & 7.3142 \\
\hline
\end{tabular}

${ }^{\mathrm{a}}$ Abbreviation: Least Significant Difference.

Table 4. Effect of Different Carbon Sources on Growth $(\mathrm{g} / 100 \mathrm{~mL})$, Ochratoxin A Production and Kinetic Production of Ochratoxin A by Aspergillus carbonarius

\begin{tabular}{lccc}
\hline Carbon Sources & Growth, $\mathbf{g} / \mathbf{1 0 0} \mathbf{~ m L}$ & OTA Production, $\boldsymbol{\mu} \mathbf{g} / \mathbf{1 0 0} \mathbf{~ m L}$ & Kinetic Production of OTA \\
\hline Fructose & 1.92974 & 132.546 & 69.48627 \\
\hline Glucose & 2.0095 & 112.91 & 56.23746 \\
\hline Sucrose & 2.08144 & 115.414 & 56.17451 \\
\hline Mannose & 0.63816 & 20.298 & 33.35953 \\
\hline Glycerol & 0.297994 & 5.294 & 18.53073 \\
\hline CMC & 0.41362 & 9.522 & 23.50932 \\
\hline Cellulose & 0.4293 & 23.664 & 56.00268 \\
\hline Starch & 0.73894 & 9.766 & 13.26897 \\
\hline Pectin & 0.31866 & 8.886 & 28.08619 \\
\hline LSD at: $\mathbf{0 . 0 5}{ }^{\text {a }}$ & 0.13 & 12.01 & 10.64 \\
\hline
\end{tabular}

a Abbreviation: Least Significant Difference. 
Hashem A et al.

Table 5. Effect of Different Nitrogen Sources on Growth $(\mathrm{g} / 100 \mathrm{ml})$, Ochratoxin A Production and Kinetic Production of Ochratoxin A by Aspergillus carbonarius

\begin{tabular}{lccc}
\hline Nitrogen Sources & Growth, $\mathbf{g} / \mathbf{1 0 0} \mathbf{~} \mathbf{L}$ & OTA production, $\boldsymbol{\mu} \mathbf{g} / \mathbf{1 0 0} \mathbf{~ m L}$ & Kinetic production of OTA \\
\hline Na-Nitr & 2.14568 & 152.614 & 71.33758 \\
\hline K-Nitr & 1.86696 & 155.704 & 84.162 \\
\hline Amm. Nitr & 2.38324 & 209.596 & 87.8686 \\
\hline Amm. Chlor & 1.04334 & 80.04 & 76.82506 \\
\hline Amm. Sulph & 1.1914 & 44.844 & 37.87001 \\
\hline Amm. Phos & 1.58246 & 116.9 & 75.78982 \\
\hline Urea & 1.24236 & 12.75 & 10.47308 \\
\hline Peptone & 2.8915 & 175.788 & 60.7099 \\
Yeast Extract & 3.08356 & 156.34 & 50.70023 \\
\hline LSD at: $\mathbf{0 . 0 5}^{\text {a }}$ & 0.1704 & 18.64 & 12.029 \\
\hline
\end{tabular}

a Abbreviation: Least Significant Difference.

Table 6. Effect of Different Water Activities (aw) on Growth (g/100 mL), Ochratoxin A Production and Kinetic Production of Ochratoxin A, Spore Germination (\%) and Germ Tube Length $(\mu \mathrm{m})$ of Aspergillus carbonarius

\begin{tabular}{lccccc}
\hline Water activity, $\mathbf{a}_{\mathrm{w}}$ & Growth, g/100 $\mathbf{~ m L}$ & $\begin{array}{c}\text { OTA Production, } \\
\mu \mathbf{g} / \mathbf{1 0 0} \mathbf{~ m L}\end{array}$ & $\begin{array}{c}\text { Kinetic } \\
\text { Production of OTA }\end{array}$ & $\begin{array}{c}\text { Spore } \\
\text { Germination, \% }\end{array}$ & $\begin{array}{c}\text { Germ Tube Length, } \\
\mu \mathbf{m}\end{array}$ \\
\hline Control & 1.60968 & 124.796 & 81.54926 & 85.6 & 114.4 \\
$\mathbf{0 . 9 8}$ & 2.06064 & 168.538 & 87.34021 & 90.0 & 138.8 \\
$\mathbf{0 . 9 0}$ & 1.0476 & 24.89 & 24.27601 & 21.6 & 28.8 \\
$\mathbf{0 . 8 5}$ & 0.3553 & 9.006 & 26.75624 & 9.4 & 13 \\
$\mathbf{0 . 8 0}$ & $\mathrm{ND}$ & $\mathrm{ND}$ & $\mathrm{ND}$ & $\mathrm{ND}$ & $\mathrm{ND}$ \\
\hline LSD at: $\mathbf{0 . 0 5}^{\mathrm{a}}$ & 0.18 & 13.27 & 5.23 & 3.72 & 14.03 \\
\hline
\end{tabular}

a Abbreviation: Least Significant Difference.

Table 7. Effect of Postharvest Treatment with Lethal Level of Water Activity (aw) on Ochratoxin A Production ( $\mu$ g/g), Weight loss (\%), Firmness (unit) and Decay Incidence (\%) of Grape Grape Fruits

\begin{tabular}{lcccc}
\hline Water activity, $\mathbf{a}_{\mathrm{w}}$ & OTA Production, $\mu \mathrm{g} / \mathbf{g}$ & Weight Loss, $\%$ & Firmness, Unit & Decay incidence, \% \\
\hline Control & 14.6 & 11.438 & 0.896 & 77.992 \\
$\mathbf{0 . 8 0}$ & 0.48 & 1.654 & 3.126 & 3.968 \\
LSD at: $\mathbf{0 . 0 5}^{\mathrm{a}}$ & 8.45 & 7.36 & 0.27 & 25.41 \\
\hline
\end{tabular}

a Abbreviation: Least Significant Difference.

\section{Discussion}

The growth and OTA production increased gradually, and the maximum was found after ten and eight days, respectively. However, the optimum incubation period for kinetic production of OTA was eight days. Thereafter, increase in the incubation period was accompanied with a decrease in growth and OTA production. Our results corroborates with the findings of Techarat and Cheewanun, (24) who reported that the maximum OTA production was obtained during the stationary phase. The incubation period, during the transport of TGF, is an important factor to predict possible OTA contamination of grapes. The results show that A. carbonarius was able to grow at wide range of incubation temperatures $\left(10-40^{\circ} \mathrm{C}\right)$ with optimum growth at $25^{\circ} \mathrm{C}$. The results are in accordance with earlier studies on A. carbonarius (6, 21) and other related species, such as A. sclerotioniger (25) and $A$. lacticoffeatus (25). The optimum temperatures for extracellular and kinetic OTA production were $20^{\circ} \mathrm{C}$ and $15^{\circ} \mathrm{C}$, respectively. Further increase in temperature, more than $20^{\circ} \mathrm{C}$ and $25^{\circ} \mathrm{C}$, significantly decreases OTA production and growth of $A$. carbonarius, respectively. At $40^{\circ} \mathrm{C} A$. carbonarius showed very weak growth and no sign of OTA production.

Our results are consistent with the findings of Copetti et al. (21), Alborch et al. (9), and Techarat and Cheewanun, (24) who independently reported that the optimal tem- 
Hashem A et al.

perature for maximum OTA production of A. carbonarius is between $20-25^{\circ} \mathrm{C}$. Generally, the optimum temperature for OTA production was reported to be lower than that for the growth of $A$. carbonarius $(6,9,24)$. The concentration of hydrogen ion ( $\mathrm{pH}$ value) in the culture medium is an important factor for growth and activity of fungi in agricultural industry and during storage of food. The increase in mycelial growth and extracellular production of OTA by A. carbonarius was directly proportional to the increase in $\mathrm{pH}$ up to 4.5 and 4.0 , respectively; and after this point a decrease was observed with increase in $\mathrm{pH}$ value. Our results corroborates with the findings of Kapetanakou et al. (13) and Spadaro et al. (26) who also reported that the optimum $\mathrm{pH}$ values for growth and OTA production by different $A$. carbonarius isolates are 4.0-4.5. Lasram et al. (27) also demonstrated that a low $\mathrm{pH}$ level is optimal for maximum OTA production by $A$. carbonarius.

In the present study both growth and OTA production of $A$. carbonarius were variable with different carbon sources. No significant difference has been observed between fructose, sucrose and glucose, which were the most suitable carbon sources for maximum mycelial growth compared with other carbon sources (Table 4). Also it is clear that fructose was the best for extracellular and kinetic OTA production (Table 4). Our results are in agreement with those of Medina et al. (28) who reported that sucrose and glucose were the most favorable for maximum growth of Aspergillus spp. (A. ochraceus, A. carbonarius and A. tubingensis). Minimum growth and OTA production were detected with glycerol as the sole carbon source followed by pectin and cellulose. Abbas et al. (29) also reported that glycerol appears to repress OTA production by A. ochraceus. It was observed that glycerol increases the viscosity and matric potential (water activity) of the culture medium hence decreases germination, growth and metabolic activities of fungi (30).

The results related to the effect of different nitrogen sources on growth and OTA production and kinetic production of OTA by A. carbonarius are depicted in Table 5 . The organic (peptone, yeast extract) and inorganic (sodium nitrates, potassium nitrates, ammonium nitrate, ammonium chloride, ammonium sulfate, ammonium phosphate and urea) nitrogen sources showed significant impact on growth, OTA production and kinetic OTA production by A. carbonarius. Maximum growth and OTA production were reported for yeast extracts followed by ammonium nitrate. However less effect was observed with ammonium chloride and urea. Similar results for growth and mycotoxin production of many fungi were also reported by Astoreca (31). Organic nitrogen sources (peptone and yeast extract) provide the required vitamins, micronutrients and intermediate compounds for the molds and might act as stimulators and precursors essentially for optimum growth and OTA production. However the hydrolysis of ammonium sulfate and urea leads to a significant effect on hydrogen ion concentration of the growth medium, which may negatively influence fungal activities (32-34). In another context, natural sources of nitrogen trigger the expression of mycotoxin biosynthetic genes and therefore the production of the mycotoxin increases (35).

The results showed that mycelial growth, spore germination, germ tube length and OTA production increase significantly by $28.01 \%, 5.14 \%, 21.32 \%$ and $35.05 \%$, respectively at $\mathrm{a}_{\mathrm{w}} 0.98$, as compared to the control. Similarly, Sepcic et al. (36) reported that sub-inhibitory doses induced growth and production of bioactive metabolites such as mycotoxins in halophilic and halotolerant fungi. A further increase in water potential $\left(0.9,0.85 \mathrm{a}_{\mathrm{w}}\right)$ caused a decrease in all growth characters (mycelial growth, spore germination and germ tube length) and OTA production of $A$. carbonarius, and no sign of growth was observed at $0.8 \mathrm{a}_{\mathrm{w}}$. The inhibitory effect of $\mathrm{a}_{\mathrm{w}}$ on growth and OTA production has been demonstrated against many food borne fungi such as Aspergillus carbonarius (37), A. niger (21), A. ochraceus (28) and Penicillium verrucosum (38). Ochratoxin A contamination in diets has been reported as the main cause of death for many children (39). Due to the increasing number of resistant fungal strains and the impact of fungicides on the environment and human health (40) a non-chemical strategy should be adapted to regulate contamination $(11,12)$. Apparently, water activity could reduce both OTA production (by 96.7\%) and the deterioration of fruit quality, which is expressed as weight loss, firmness and decay (by 85.5\%, 71.3\% and 94.9\%, respectively) as compared to the control. Tassou et al. (41) and Lasram et al. (42) also reported that deterioration of TGF by $A$. carbonarius could be minimized by application of $\mathrm{a}_{\mathrm{w}}$. Our results supported their concept at conditions of local markets, which support the economy of many thousands of families in Egypt, especially in the poor rural areas. In future adequate research is required to use these technologies commercially.

\section{Acknowledgements}

The authors are thankful to the College of Applied Studies and Community Service and the Deanship of Scientific Research, King Saud University, Saudi Arabia for providing funds for this research. 
Hashem A et al.

\section{References}

1. Magan N, Olsen M. Mycotoxins in food: detection and control.: Woodhead Publishing; 2004

2. Palma N, Cinelli S, Sapora O, Wilson SH, Dogliotti E. Ochratoxin A-induced mutagenesis in mammalian cells is consistent with the production of oxidative stress. Chem Res Toxicol. 2007;20(7):1031-7.

3. Kamp HG, Eisenbrand G, Schlatter J, Wurth K, Janzowski C. Ochratoxin A: induction of (oxidative) DNA damage, cytotoxicity and apoptosis in mammalian cell lines and primary cells. Toxicology. 2005;206(3):413-25.

4. Abrunhosa L, Paterson RR, Venancio A. Biodegradation of ochratoxin a for food and feed decontamination. Toxins (Basel). 2010;2(5):1078-99.

5. Youssef MS, Abo-Dahab NF, Abou-Seidah AA. Mycobiota and mycotoxin contamination of dried raisins in Egypt. Afr J Mycol Biotechnol. 2000;8(3):69-86.

6. Atoui A, Mitchell D, Mathieu F, Magan N, Lebrihi A. Partitioning of ochratoxin A in mycelium and conidia of Aspergillus carbonarius and the impact on toxin contamination of grapes and wine. J Appl Microbiol. 2007;103(4):961-8.

7. Alisa D, Su-lin L, Benozir A, Robert W, Eileen S. Fungi and mycotoxins in vine tards and grape production. Int J Food Microbiol. 2007;119(1-2):84-8.

8. Prusky D. Reduction of the incidence of postharvest quality losses, and future prospects. Food Sec. 2011;3(4):463-74.

9. Alborch L, Bragulat MR, Abarca ML, Cabanes FJ. Temperature and incubation time effects on growth and ochratoxin A production by Aspergillus sclerotioniger and Aspergillus lacticoffeatus on culture media. Lett Appl Microbiol. 2011;52(3):208-12.

10. Medina A, Mateo R, Valle-Algarra FM, Mateo EM, Jimenez M. Effect of carbendazim and physicochemical factors on the growth and ochratoxin A production of Aspergillus carbonarius isolated from grapes. Int J Food Microbiol. 2007;119(3):230-5.

11. Ponsone ML, Chiotta ML, Palazzini JM, Combina M, Chulze S Control of ochratoxin A production in grapes. Toxins (Basel). 2012;4(5):364-72.

12. Abeer H, Abd-Allah EF, Al-Obeed RS, Mridha MAU, Al-Huqail AA Non-chemical strategies to control postharvest losses and extend the shelf life of table grape fruits. Biol Agri Hort. 2013;29(2):82-90.

13. Kapetanakou AE, Panagou EZ, Gialitaki M, Drosinos EH, Skandamis PN. Evaluating the combined effect of water activity, $\mathrm{pH}$ and temperature on ochratoxin A production by Aspergillus ochraceus and Aspergillus carbonarius on culture medium and Corinth raisins. Food Control. 2009;20(8):725-32.

14. Magan N, Aldred D, Hope R, Mitchell D. Environmental factors and interactions with mycobiota of grain and grapes: effects on growth, deoxynivalenol and ochratoxin production by Fusarium culmorum and Aspergillus carbonarius. Toxins (Basel). 2010;2(3):353-66.

15. Ni X, Streett DA. Modulation of water activity on fungicide effect on Aspergillus niger growth in Sabouraud dextrose agar medium. Lett Appl Microbiol. 2005;41(5):428-33.

16. Raper BK, Fennell DI. The Genus Aspergillus.Baltimore: Williams and Wilkins; 1965.

17. Brian PW, Dawkins AW, Grove JF, Hemming HG, Lowe D, Norris GLF. Phytotoxic Compounds produced byFusarium equiseti. $J$ Exp Bot.1961;12(1):1-12.

18. Pardo E, Ramos AJ, Sanchis V, Marin S. Modelling of effects of water activity and temperature on germination and growth of ochratoxigenic isolates of Aspergillus ochraceus on a green coffeebased medium. Int J Food Microbiol. 2005;98(1):1-9.

19. Scott PM. Mycotoxins and Food Safety. Springer; 2002. pp. 117-34. Methods of analysis for ochratoxin A.

20. Aboul-Enein HY, Kutluk OB, Altiokka G, Tuncel M. A modified HPLC method for the determination of ochratoxin A by fluorescence detection. Biomed Chromatogr. 2002;16(7):470-4.

21. Copetti MV, Iamanaka BT, Mororo RC, Pereira JL, Frisvad JC, Taniwaki MH. The effect of cocoa fermentation and weak organic acids on growth and ochratoxin A production by Aspergillus species. Int J Food Microbiol. 2012;155(3):158-64.

22. Valero A, Sanchis V, Ramos AJ, Marin S. Brief in vitro study on
Botrytis cinerea and Aspergillus carbonarius regarding growth and ochratoxin A. Lett Appl Microbiol. 2008;47(4):327-32.

23. Holz G, Gütschow M, Coertze S, Calitz FJ. Occurrence of Botrytis cinerea and subsequent disease expression at different positions on leaves and bunches of grape. Plant Dis. 2003;87(4):351-8.

24. Techarat S, Cheewanun D. Growth and Ochratoxin A production of black aspergilli isolated from Thai wine grapes. As J Food AgInd. 2012;5(3):172-82.

25. Samson RA, Noonim P, Meijer M, Houbraken J, Frisvad JC, Varga J. Diagnostic tools to identify black aspergilli. Stud Mycol. 2007;59:129-45.

26. Spadaro D, Patharajan S, Lorè A, Gullino ML, Garibaldi A. Effect of $\mathrm{pH}$, water activity and temperature on the growth and accumulation of ochratoxin A produced by three strains of Aspergillus carbonarius isolated from Italian vineyards. Phytopathol Mediterr. 2010;49(1):65-73.

27. Lasram S, Barketi A, Mliki A, Ghorbel A. Growth and ochratoxin A production by Aspergillus carbonarius at different $\mathrm{pHs}$ and grape maturation stages. Lett Appl Microbiol. 2012;54(5):418-24.

28. Medina A, Mateo EM, Valle-Algarra FM, Mateo F, Mateo R, Jimenez $M$. Influence of nitrogen and carbon sources on the production of ochratoxin A by ochratoxigenic strains of Aspergillus spp. isolated from grapes. Int J Food Microbiol. 2008;122(1-2):93-9.

29. Abbas A, Valez H, Dobson AD. Analysis of the effect of nutritional factors on OTA and OTB biosynthesis and polyketide synthase gene expression in Aspergillus ochraceus. Int J Food Microbiol. 2009;135(1):22-7.

30. Alborch L, Bragulat MR, Abarca ML, Cabanes FJ. Effect of water activity, temperature and incubation time on growth and ochratoxin A production by Aspergillus niger and Aspergillus carbonarius on maize kernels. Int J Food Microbiol. 2011;147(1):53-7.

31. Astoreca A, Barberis C, Magnoli C, Combina M, Dalcero A. Ecophysiological factor effect on growth rate, lag phase and ochratoxin A production by Aspergillus niger aggregate strains on irradiated peanut seeds. Int J Food Microbiol. 20 09;129(2):131-5.

32. Kapetanakou AE, Ampavi A, Yanniotis S, Drosinos EH, Skandamis PN. Development of a model describing the effect of temperature, water activity and (gel) structure on growth and ochratoxin A production by Aspergillus carbonarius in vitro and evaluation in food matrices of different viscosity. Food Microbiol. 2011;28(4):727-35.

33. Oueslati S, Lasram S, Ramos AJ, Marin S, Mliki A, Sanchis V, et al. Alternating temperatures and photoperiod effects on fungal growth and Ochratoxin A production by Aspergillus carbonarius isolated from Tunisian grapes. Int J Food Microbiol. 2010;139(3):210-3.

34. Brzonkalik K, Hümmer D, Syldatk C, Neumann A. Influence of $p H$ and carbon to nitrogen ratio on mycotoxin production by Alternaria alternata in submerged cultivation.: AMB Express;2012.

35. Kohut G, Adam AL, Fazekas B, Hornok L. N-starvation stress induced FUM gene expression and fumonisin production is mediated via the HOG-type MAPK pathway in Fusarium proliferatum. Int J Food Microbiol. 2009;130(1):65-9.

36. Sepcic K, Zalar P, Gunde-Cimerman N. Low water activity induces the production of bioactive metabolites in halophilic and halotolerant fungi. Mar Drugs. 2011;9(1):43-58.

37. Romero SM, Pinto VF, Patriarca A, Vaamonde G. Ochratoxin A production by a mixed inoculum of Aspergillus carbonarius at different conditions of water activity and temperature. Int J Food Microbiol. 2010;140(2-3):277-81.

38. Aldred D, Cairns-Fuller V, Magan N. Environmental factors affect efficacy of some essential oils and resveratrol to control growth and ochratoxin A production by Penicillium verrucosum and Aspergillus westerdijkiae on wheat grain. J Stored Prod Res. 2008;44(4):341-6.

39. Romero SM, Patriarca A, Fernandez Pinto V, Vaamonde G. Effect of water activity and temperature on growth of ochratoxigenic strains of Aspergillus carbonarius isolated from Argentinean dried vine fruits. Int J Food Microbiol. 2007;115(2):140-3.

40. De Costa P, Bezerra P. Fungicides: Chemistry, Environmental Impact and Health Effects.Waltham: Nova Biomedica; 2009.

41. Tassou CC, Natskoulis PI, Magan N, Panagou EZ. Effect of temperature and water activity on growth and ochratoxin A production 


\section{Hashem A et al.}

boundaries of two Aspergillus carbonarius isolates on a simulated grape juice medium. J Appl Microbiol. 2009;107(1):257-68.

42. Lasram S, Oueslati S, Valero A, Marin S, Ghorbel A, Sanchis V. Wa- ter activity and temperature effects on fungal growth and ochratoxin A production by ochratoxigenic Aspergillus carbonarius isolated from Tunisian grapes. J Food Sci. 2010;75(2):M89-97. 